\title{
Prevalence \& Consequences of Anaemia in Pregnancy
}

\author{
Dayal S', Dayal A $\mathbf{A}^{2}$ \\ ${ }^{1}$ Dr Sheetal Dayal, Assistant Professor of Obstetrics \& Gyenecology, L N Medical College, Bhopal, ${ }^{2}$ Dr Achleshwar Dayal, \\ Associate Professor, Department of Surgery, L N Medical College, Bhopal, India
}

Address for correspondence: Dr Sheetal Dayal, Email: dradayal@yahoo.com

\begin{abstract}
Introduction: This study is planned with aim to identify prevalence of anaemia in specified population in south India and to know various adverse consequences of anaemia in mother and child. Methods: This is a prospective observational study done in pregnant women indicates anaemia in pregnancy is a risk factor for low birth weight(LBW), preterm delivery, poor APGAR score and possibly early neonatal death. Results: After comparison with non anaemic and anaemic group we fond that there is 2.5 to 3.5 times increase in LBW, preterm delivery and early neonatal death in anaemic group. WHO criteria is used for classification of anaemia and we found $60 \%$ of our study population are anaemic. Conclusion: This study conform the recommendations of various previous studies that anaemia is strongly associated with LBW, preterm delivery and early neonatal death.
\end{abstract}

Keywords: Anemia in Pregnancy, Low birth weight, Prevalence of anaemia in pregnancy

\section{Introduction}

Womens of child bearing age group are at the maximum risk for development of anaemia. Anaemia is the most common nutritional deficiency disorder in the world. WHO has estimated that prevalence of anaemia in developed countries is $14 \%$ and in developing countries is $51 \%$ in pregnant women. Prevalence of anaemia in India is $65-75 \%$ in pregnant women [1]. Specially Iron deficiency anaemia is important public health problem for pregnant women, living in developing countries, affecting $2 / 3^{\text {rd }}$ of pregnant women and contributes to maternal morbidity and mortality and to low birth weight [2-3]. High prevelance is directory associated with poor health status, poverty, poor socioeconomic status, multiparty, less birth spacing and many more.

Anaemia is defined by WHO as Haemoglobin ( $\mathrm{Hb})$ less than $11 \mathrm{gm}$ in pregnancy, and is divided into three degrees mild (10.9-9.0 gm \%), moderate (8.9-7.0 gm \%) and severe degree $(<7.0 \mathrm{gm} \%)$ [4] and we used these parameter in study.

Most of the studies have demonstrated a strong association between maternal anaemia and adverse outcome such as low birth weight, preterm delivery and intrauterine growth retardation [5-9].

This study is planned to find the incidence and

Manuscript received: $22^{\text {nd }}$ Jan 2014

Reviewed: $20^{\text {th }}$ Feb 2014

Author Corrected: $23^{\text {rd }} \mathrm{Feb} 2014$

Accepted for Publication: $2^{\text {nd }}$ Mar 2014 prevalence of anaemia in pregnant mother in specified population and to investigate their adverse outcome in mother and new born baby.

\section{Methodology}

The present study is a "prospective" observational study which is conducted in tertiary care teaching hospital of South India for 6 months. In the study period, 442 booked cases were studied, among which 214 cases were primigravidae and 228 cases were multigravidae.

In this study, pregnant woman attending out patient's department or casualty after 12 weeks of gestation till delivery having singleton pregnancy were included in the study. Complete blood count was performed to assess $\mathrm{Hb}$ level after 12 week and at the time of engagement and average of both reading was taken in study.

\section{Inclusion criteria}

Pregnant woman who delivered in our institute were included in this study.

\section{Exclusion criteria \\ Multiparty (5 and above) \\ Hypertensive disorders in pregnancy \\ Pregnancy with diabetes mellitus \\ Ante partum haemorrhage \\ Pregnancy with chronic medical illness \\ Multiple gestations}


$\square$ HIV/HBsAg/VDRL positive cases

\section{Observations \& Results}

In the present study, total numbers of booked cases studied were 442, out of which 214 cases were primigravidae and 228 were multigravidae.

Table No: 1 - Age wise distribution of patients

\begin{tabular}{|l|l|l|}
\hline Age Group & No of Patients & Percentage \\
\hline$<19$ Years & 28 & 6.33 \\
\hline $20-35$ & 313 & 70.81 \\
\hline$>35$ & 101 & 22.85 \\
\hline Total No & 442 & 100 \\
\hline
\end{tabular}

In the present study, 313 cases were in age group 20 - 34 years, which comprises $70.81 \%$ of total, number of teenage pregnancies were $28(6.33 \%)$ in the study. Nearly one fourth of pregnancies were more than 35 years of age. $48.41 \%$ of cases were primigravidae and $51.58 \%$ were multigravidae.

Table No 2: Incidence \& Severity of Anaemia in study population

\begin{tabular}{|c|c|c|c|c|c|}
\hline $\mathbf{H b}$ & $\begin{array}{l}\text { Non-Anaemic } \\
(>11 \mathrm{mg} \%)\end{array}$ & $\begin{array}{l}\text { Mild } \\
(10.9-9 \text { gm \% ) }\end{array}$ & $\begin{array}{l}\text { Moderate } \\
(8.9-7 \text { gm \%) }\end{array}$ & $\begin{array}{l}\text { Severe } \\
(<7 \text { gm \%) }\end{array}$ & \\
\hline Primigravidae & 99 & 29 & 82 & 4 & $\mathrm{~N}=214$ \\
\hline Multigravidae & 73 & 47 & 101 & 7 & $\mathrm{~N}=228$ \\
\hline Total No & $\mathrm{N}=172$ & $\mathrm{~N}=76$ & $\mathrm{~N}=183$ & $\mathrm{~N}=11$ & \\
\hline Percentage & $38.91 \%$ & $17.19 \%$ & $41.4 \%$ & $2.47 \%$ & \\
\hline
\end{tabular}

In the present study, 183 cases had moderate anaemia giving an incidence of $41.41 \%, 76$ cases in the study group had mild anemia with an incidence of $17.19 \%, 11$ cases had $\mathrm{Hb}<7 \mathrm{gm}$ giving an incidence of $2.47 \%$ which are severely anaemic. Maximum numbers of primigravidae (99) were Non-anemic while maximum number of multigravida (101) have moderate anemia.

Table No 3: Comparison of birth weight between non-anaemic and anaemic groups.

\begin{tabular}{|c|l|l|l|l|l|}
\hline Birth Weight & Non Anaemic & Mild Anaemic & $\begin{array}{l}\text { Moderate } \\
\text { Anaemic }\end{array}$ & Severe Anaemic & \\
\hline$<2 \mathrm{Kg}$ & $12(7 \%)$ & $15(20 \%)$ & $37(20 \%)$ & $\mathbf{6 ~ ( 5 2 \% )}$ & $\mathrm{N}=70$ \\
\hline $2-2.5 \mathrm{Kg}$ & $43(25 \%)$ & $42(55 \%)$ & $100(54 \%)$ & $3(28 \%)$ & $\mathrm{N}=188$ \\
\hline$>2.5 \mathrm{Kg}$ & $117(68 \%)$ & $19(25 \%)$ & $46(24 \%)$ & $2(20 \%)$ & $\mathrm{N}=184$ \\
\hline Total & $\mathrm{N}=172$ & $\mathrm{~N}=76$ & $\mathrm{~N}=183$ & $\mathrm{~N}=11$ & \\
\hline
\end{tabular}

In the present study in non anaemic group $68 \%$ of new born baby have birth weight $>2.5 \mathrm{~kg}$.

In mild- moderate anaemic group about $55 \%$ of new born baby have birth weight $2-2.5 \mathrm{~kg}$. But in severely anaemic group $52 \%$ of new born baby have birth weight $<2 \mathrm{~kg}$.

If we compare neonate with birth weight $<2 \mathrm{~kg}$ were $7 \%$ in non-anaemic group and $52 \%$ in severely anaemic group; that is 7 times more than non-anaemic group. 
Table No 4 - Comparison of neonatal outcome between non-anaemic and anaemic groups.

\begin{tabular}{|l|l|l|l|l|l|}
\hline Variables & Non-Anaemic & $\begin{array}{l}\text { Mild } \\
\text { Anaemic }\end{array}$ & $\begin{array}{l}\text { Moderate } \\
\text { Anaemic }\end{array}$ & $\begin{array}{l}\text { Severe } \\
\text { Anaemic }\end{array}$ & \\
\hline Preterm delivery & $35(20 \%)$ & $38(50 \%)$ & $100(55 \%)$ & $7(70 \%)$ & $5(45 \%)$ \\
\hline $\begin{array}{l}\text { Poor APGAR Score (at 5 } \\
\text { min <7) }\end{array}$ & $17(10 \%)$ & $19(25 \%)$ & $51(28 \%)$ & $5(45 \%)$ & \\
\hline Early neonatal death & $5(3 \%)$ & $3(4 \%)$ & $9(5 \%)$ & & \\
\hline
\end{tabular}

Pre term delivery in non-anaemic group was $20 \%$ while it was 2.5 times and 3.5 times more in mild- moderately anaemic group and severely anaemic group respectively.

Poor APGAR score (taken at 5 minutes $<7$ ) was $10 \%$ in non-anaemic group and it was increased to 2.6 times in mildmoderately anaemic group and 4.5 times in severely anaemic group.

Early neonatal death was $3 \%$ in non-anaemic group and while it was 1.4 times and 15 times more in mild- moderately anaemic group and severely anaemic group respectively.

\section{Discussion}

In our study $71 \%$ of booked cases were between $20-35$ years of age group it means child bearing is common at younger age group. In our study $60 \%$ of study population were anaemic in which $41.4 \%$ have moderate anaemia as per WHO guidelines. Incidence of anaemia is more in multigravida as compared to primigravida. Many studies however, shown that young maternal age and parity are significant risk factors of LBW [10,11].

In our study the risk of low birth weight is more in anaemic group and it increases with severity of anaemia. In mild- moderate anaemic group about $55 \%$ of new born baby have birth weight $2-2.5 \mathrm{~kg}$. But in severely anaemic group $52 \%$ of new born baby have birth weight $<2 \mathrm{~kg}$. A similar condition was observed in Pakistan in which majority of the cases had mild anaemia (75.0\%), moderate anaemia $(14.8 \%)$ and severe anaemia $(0.7 \%)$ [12]. Similarly, report from India in 2010 also showed the majority $(50.9 \%)$ of patients having moderate anaemia followed by mild (30.17\%) and severe anaemia (18.9\%) respectively $[6,13]$.

Low birth weight babies are more commonly associated with severe Anemia. These results are similar to studies done previously by Rani KU et al [14], Jain P. et al [5] and Levy et a 1[6].

In our study risk of preterm delivery is more in anaemic group and which increases with severity of anaemia from 50 to $70 \%$, these results shows similarity with study done by Rani KU et al [14], Jain P et al [5] and Umber et al [9].

There are many studies showing that maternal iron deficiency anaemia early in pregnancy can result in low birth weight subsequent to preterm delivery. One study on welsh women who were first diagnosed with anaemia (haemoglobin $<10 \mathrm{~g} \%$ ) at 13-24 wk of gestation had a 1.18-1.75-fold higher relative risk of preterm birth, low birth weight, and prenatal mortality [15]. After controlling for many other variables in a large Californian study, Klebanoff et al showed a doubled risk of preterm delivery with anaemia [16].

In our study preterm and low birth weight among mild and moderate anaemic women was 2.5 and 3 times more than non-anaemic group. Study done by Umber et al [9] that has showed risk of preterm and low birth weight were 3.4 and 1.8 times more in anaemic group. They have taken two group for study, anaemic $<11 \mathrm{gm} \% \mathrm{Hb}$ and non-anaemic $>11 \mathrm{gm} \% \mathrm{Hb}$. They have also shown poor APGAR score in anaemic group which supports our study.

In our study chances of early neonatal death are increases with anaemia severity. An association between maternal anaemia and lower infant APGAR scores was reported in some study done by Rusia et al [8] in 102 Indian women in the first stage of labour, higher maternal haemoglobin concentrations were correlated with better APGAR scores and with a lower risk of birth asphyxia. Study done by Ram Hari et al [17] showed perinatal death 5\% in nonanaemic group \& $11 \%$ in severely anaemic group. Present study also shows early neonatal death $3 \%$ in nonanaemic group and $45 \% \%$ in severely anaemic group

\section{Conclusion}

In developing countries like India prevalence of anaemia is very high which adversely affect both maternal and foetal outcome. Anaemia is s directly linked to low birth weight, prematurity, poor APGAR score and neonatal death and maternal morbidity and mortality. To combat all these problems there is a need to prevent incidence of anaemia in pregnant women by giving, iron tablet, food supplements, better antenatal care and by giving health education. These measures are affordable and easily available in our country and by effective implementation of these we can save many lives of both mother and child. 
Funding: Nil

Conflict of interest: Nil

Permission from IRB: Yes

\section{References}

1. DeMayer EM, Tegman A. Prevalence of anaemia in the World. World Health Organ Qlty 1998; 38 : 302-16.

2. Pasricha SR, Caruana SR, Phuc TQ, Casey GJ, Jolley $\mathrm{D}$, Kingsland S, et al. Anemia, iron deficiency, meat consumption, and hookworm infection in women of reproductive age in northwest Vietnam. Am J Trop Med Hyg. 2008 78(3):375- 81.

3. Baig-Ansari N, Badruddin SH, Karmaliani R, Harris $\mathrm{H}$, Jehan I, Pasha O, et al. Anemia prevalence and risk factors in pregnant women in an urban area of Pakistan Food Nutr Bull, 2008; 29(2):132-9.

4. Marahatta R. Study of anaemia in pregnancy and its outcome in Nepal Medical College Teaching Hospital, Kathmandu, Nepal. Nepal Med Coll J, 2007;9:270-4.

5. Jain Preeti, Kural M, Joshi Tulika. Maternal and fetal outcome in cases of severe anaemia with pregnancy in rural set up. Int J Med Appl Sci. 2013;2(3):318-33.

6. Levy a, Fraser D, Katz M, Mazor M, Sheiner E. Maternal anaemia during pregnancy is an independent risk factor for low birth weight and preterm delivery. Eur J Obstet Gynecol Reprod Biol. 2005;122(2):182-6.

7. Hussein L. Kidanto, Ingrid Mogren, Gunilla Lindmark, Siriel Massawe, Lennarth Nystrom. Risks for preterm delivery and low birth weight are independently increased by severity of maternal anaemia. South African Med J. 2009;99(2):98-102.

8. Rusia U, Madan N, Agarwal N, Sikka M, Sood SK. Effect of maternal iron deficiency anaemia on foetal outcome. Indian J Pathol Microbiol. 1995;38:273-9.
9. Umber Jalil Bakhtiar, Yasmeen Khan, Razia Nasar. Relationship between maternal haemoglobin and perinatal outcome. Rawal Med J. 2007;32(2):102-4.

10. Mann LI, Tejani NA, Weiss RR. Antenatal diagnosis and management of small for gestational age fetus. Am J Obstet Gynecol. 1974;120:995-1004.

11. Viengsakhone L, Yoshida Y, Harun-Or-Rashid M, Sakamoto J. Factors affecting low birth weight at four central hospitals in vientiane, Lao PDR. Nagoya J Med Sci. 2010;72:51-8.

12. Baig-Ansari N, Badruddin SH, Karmaliani R, Harris H, Jehan I, Pasha O, Moss N, McClure EM, Goldenberg RL. Anemia prevalence and risk factors in pregnant women in an urban area of Pakistan. Food Nutr Bull 2008; 29:132-1399.

13. Vijaynath 1, Jitendra 1, Ramesh $\mathrm{P}$, Abhishek $\mathrm{P}$. Prevalence of anemia in pregnancy. Indian Journal of Applied Basic Medical Sciences 2010; 12:23-35.

14.Rani U., Gupta J, Gupta R, Aggarwal K. Maternal anaemia and its severity: an independent risk factor for preterm delivery and adverse neonatal outcome. Int $\mathrm{J}$ Reprod Contracept Obstet Gynecol. 2014 Jun;3(2):325329

15. Murphy JF, O’Riordan J, Newcombe RJ, Coles EC, Pearson JF. Relation of hemoglobin levels in first and second trimesters to outcome of pregnancy. Lancet 1986;1:992-5.

16. Klebanoff MA, Shiono PH, Selby JV, Trachtenberg AI, Graubard BI. Anemia and spontaneous preterm birth. Am J Obstet Gynecol 1991;164:59-63.

17. Ram Hari Ghimire, Sita Ghimire. Maternal and fetal outcome following severe anaemia in pregnancy. J Nobel Med College. 2013;2(1):22-6.

\section{How to cite this article?}

Dayal S, Dayal A. Prevalence \& Consequences of Anaemia in Pregnancy. Int J Med Res Rev 2014;2(4):296- 299. doi:10.17511/ijmrr.2014.i04.05 